\title{
Analysis and Testing of a Natural Convection Solar Dryer for the Tropics
}

\author{
A. O. Adelaja and B. I. Babatope \\ The Department of Mechanical Engineering, University of Lagos, Akoka, Yaba, Lagos 101017, Nigeria \\ Correspondence should be addressed to A. O. Adelaja; ao_adelaja@yahoo.com
}

Received 12 December 2012; Revised 20 February 2013; Accepted 20 February 2013

Academic Editor: Mattheos Santamouris

Copyright (C) 2013 A. O. Adelaja and B. I. Babatope. This is an open access article distributed under the Creative Commons Attribution License, which permits unrestricted use, distribution, and reproduction in any medium, provided the original work is properly cited.

\begin{abstract}
Solar dryers are imperative for the tropical and sub-Saharan African countries, which are faced with the duo challenges of inadequate electrical energy supply, which has severely limited the application of conventional refrigeration as a means of preservation of agricultural produce, and the need to make produce competitive in the international market. In this study, a costeffective natural convection solar dryer was developed; the thermal and drying analyses were done and tested to obtain some performance evaluation parameters for the system in order to examine its efficiency and effectiveness by drying some plantain fillets. The collector and system efficiencies are found to be $46.4 \%$ and $78.73 \%$, respectively, while a percentage moisture removal of $77.5 \%$ was achieved at the 20th hour in order to give final moisture contents of $15.75 \%$ in the product, which still maintained its integrity. With a cost of about $\$ 195.00$, it has been affordable for the small- and medium-scale enterprises as well as for private use in domestic applications.
\end{abstract}

\section{Introduction}

Sun drying is the most common, economical and environmentally friendly method of preservation of agricultural produces in the tropical and sub-Saharan African regions. Open sun drying, however, has some disadvantages, of which are, undue exposure of produce to weather elements such as rain, ultraviolet rays of the sun, and contamination by wind-borne dirt and dust. Others include infestation by insects, rodents, pests and other animals as well as degradation by mucus and bacteria. These, for a long time, had made agricultural produce consumed locally, and those meant for export to fall short of the required hygienic and international standards, and hence, they are very often uncompetitive. Obviously, lack of effective preservation technology is a major stumbling block for farmers in the tropics and sub-Saharan African regions, as electricity is either inadequate or unaffordable to the small-scale farmers, thus discouraging refrigeration of the farm produce. This has left most farmers, particularly those engaged in small- and medium-scale farming, with no other option than to depend on one of the most abundant and free primary energy resources-the sun. Faced with the challenges of inadequate supply of electricity, on one hand, and the need to make farm produce competitive in the international market, on the other hand, the closest solution option is the use of solar dryer. This drying technique is in no way a new concept. Over the past four decades, there has been a steady evolution of solar dryer technology from natural convection types (direct and passive mode) to forced convection types [1-9].

The interest in the passive mode of drying rather than the direct type is the advantage it offers over the latter as it protects the produce from the harmful effects of the ultraviolet radiation of the sun, which destroys some nutrients and vitamins in the produce. Numerous works on natural convection solar types have been done by various researchers $[1-3,5,6,8,9]$.

In most of these studies, emphasis has been on the construction and testing of the system while, in some other cases, the drying analysis and/or simulation was also done. This study presents the thermal analysis as well as the system's evaluation during drying of plantain fillets. The next section 

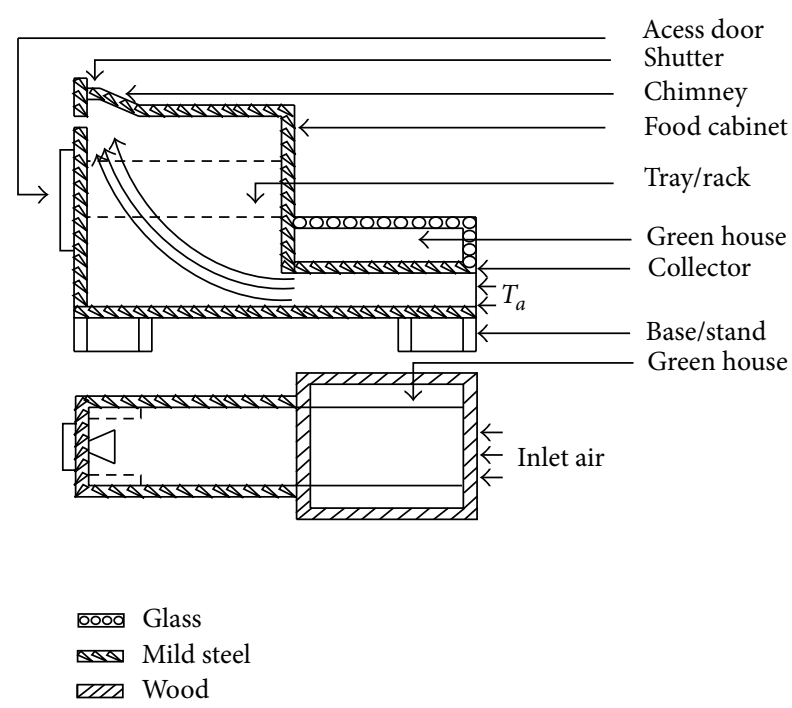

Figure 1: Diagram of solar dryer.

deals with the description of dryer and material selection followed by the design analysis in Section 3. Experimental procedure and testing are discussed in Section 4, while results and the discussion are in Section 5. Section 6 presents the cost analysis, and the conclusions drawn in Section 7.

\section{Description of Dryer and Material Selection}

The system is an $L$-shaped solar dryer which operates on the principle of natural convection (Figure 1). The base, which comprises the collector channel and collector case compartment, is connected to the food cabinet. The collector and cabinet are made of mild steel painted black on the inside and outside surfaces. This enables maximum absorption and emission of radiant heat energy by the system. The paint also serves to reduce the tendency of the metal to corrode. To facilitate the build-up of heat in the system, the collector is covered with a box which has a transparent glass at the top surface-greenhouse effect. The inlet air comes in through the metal collector channel heated and naturally rises through the food cabinet and exits through the shutter of the chimney, which is adjusted between $42 \mathrm{~cm}^{2}$ and $84 \mathrm{~cm}^{2}$ space in order to control the flow and the temperature in the cabinet. The product, plantain, is cleaned and cut into slices with a thickness of about $3 \mathrm{~mm}$ and weighed and spread on the first rack of the cabinet over which the hot air from the collector flow and remove moisture from the produce in the process.

This solar dryer is clearly different from most of the natural convection types in that it receives useful heat energy through indirect mode as a result of heated air flowing through the solar collector by buoyancy effect. Radiant heat energy is additionally absorbed by this cabinet without the exposure of the produce (article intended for drying) to the ultraviolet rays from the sun. However, some available indirect-mode natural convection solar dryers are made of plywood, but the collector covers are made of transparent glass [8]. This receives useful heat into the cabinet through
TABLE 1: Design considerations and assumptions.

\begin{tabular}{|c|c|c|}
\hline$S / N$ & Parameters & Description \\
\hline 1 & Location & $\begin{array}{l}\text { Lagos, }\left(\text { long } 3^{\circ} 24^{\prime}, \text { lat }\right. \\
\left.6^{\circ} 27^{\prime} \mathrm{N}\right)\end{array}$ \\
\hline 2 & Drying period & October \\
\hline 3 & Solar irradiation, Lagos (October) & $15.4 \mathrm{MJ} / \mathrm{m}^{2} / \mathrm{hr}[10]$ \\
\hline 4 & $\begin{array}{l}\text { Annual relative humidity of Lagos } \\
\text { taken over a ten-year period }\end{array}$ & $80 \%[11]$ \\
\hline 5 & Food products & Plantain \\
\hline 6 & Mode of heating & Indirect \\
\hline 7 & Number of glazing & 1 \\
\hline 8 & Glazing materials & Glass \\
\hline 9 & Loading provision & $\begin{array}{l}\text { Door at the back of } \\
\text { cabinet }\end{array}$ \\
\hline 10 & Number of trays & 2 \\
\hline 11 & Air outlet provision & $\begin{array}{l}\text { Chimney at the top of } \\
\text { cabinet }\end{array}$ \\
\hline 12 & Air circulation mode & Natural convection \\
\hline 13 & Drying capacity & $10 \mathrm{~kg}$ \\
\hline 14 & Thickness of plantain fillets & $3 \mathrm{~mm}$ \\
\hline 15 & Construction materials & $\begin{array}{l}\text { Wood, glass, mild } \\
\text { steel sheet }\end{array}$ \\
\hline 16 & Insulation used & Glass fiber \\
\hline 17 & Thickness of mild steel sheet & $3 \mathrm{~mm}$ \\
\hline 18 & Thickness of glass & $4.5 \mathrm{~mm}$ \\
\hline 19 & $\begin{array}{l}\text { Thermal conductivity of glass, } \\
\mathrm{W} / \mathrm{mK}\end{array}$ & $0.84[12]$ \\
\hline 20 & Transmittance of glass & 0.81 \\
\hline 21 & Emissivity of: glass & 0.94 at $72^{\circ} \mathrm{F}[13]$ \\
\hline 22 & Mild steel & $0.2-0.32[13]$ \\
\hline 23 & Paint, flat black lacquer & $0.96-0.98[13]$ \\
\hline 24 & Black or white lacquer & $0.80-0.95[13]$ \\
\hline 25 & $\begin{array}{l}\text { Thermal conductivity of mild steel, } \\
\mathrm{W} / \mathrm{m}^{\circ} \mathrm{K} \text { at } 38^{\circ} \mathrm{C}\end{array}$ & 50.0 \\
\hline 26 & Sky temperature & $32^{\circ} \mathrm{C}$ \\
\hline 27 & Dimension of collector case & $1.0 \mathrm{~m} \times 1.0 \mathrm{~m} \times 0.2 \mathrm{~m}$ \\
\hline 28 & Dimension of collector channel & $1.0 \mathrm{~m} \times 0.5 \mathrm{~m} \times 0.1 \mathrm{~m}$ \\
\hline 29 & $\begin{array}{l}\text { Initial moisture content of plantain, } \\
m_{i}\end{array}$ & $70 \%[14]$ \\
\hline
\end{tabular}

the collector. On the other hand, the mixed-mode solar dryers $[8,9]$ are made of glass; both the collector and the cover of the cabinet are made of glass. The disadvantage these may have, though they seem to be more efficient than the indirect mode, is that the ultraviolet rays of the sun reaching the produce may destroy some nutrients and vitamins.

The design parameters and consideration used for the construction of the equipment are listed in Table 1. The properties of air used are evaluated at $312.54 \mathrm{~K}$ [15], being the mean of the temperatures of air at the inlet and exit of the cabinet taken over a period of eight days during no load conditions. The average temperatures recorded in cabinet $T_{d}$, collector $T_{c}$, collector case (or greenhouse chamber) $T_{c a}$, and 
environment $T_{a}$ are $41.56^{\circ} \mathrm{C}, 47.38^{\circ} \mathrm{C}, 48.81^{\circ} \mathrm{C}$, and $31.69^{\circ} \mathrm{C}$, respectively.

\section{Design Analysis}

In this work, focus will be on the thermal and drying analyses only.

3.1. Thermal Analysis. The performance of a solar system and collector is described by an energy balance that indicates the conversion of incident solar energy into useful energy gain and various losses. The thermal analysis here follows the procedures as in Duffie and Beckman [16].

Some Properties of Air. The following air properties taken from the average temperature in the cabinet are used for the analysis (extracted from Holman [15]): $\rho=1.1324 \mathrm{~kg} / \mathrm{m}^{3}$, $c_{p}=1.0066 \mathrm{~kJ} / \mathrm{kg} \cdot{ }^{\circ} \mathrm{C}, \mu=1.9036 \times 10^{-5} \mathrm{~kg} / \mathrm{m} \cdot \mathrm{s}, \nu=$ $16.9616 \times 10^{-6} \mathrm{~m}^{2} / \mathrm{s}, k=0.02719 \mathrm{~W} / \mathrm{m} \cdot{ }^{\circ} \mathrm{C}, \operatorname{Pr}=0.70524$. These properties are used to calculate the thermal characteristics and performance of the system.

Grashof Number, Gr

$$
\mathrm{Gr}=\frac{g \beta L^{3} \Delta T}{v^{2}},
$$

where $v=\mu / \rho, \beta=1 / T, \Delta T=T_{c}-T_{a}$, and $T=\left(T_{c}+T_{a}\right) / 2$. $L$ depends on the section of the cabinet under analysis. The heat transfer coefficient is represented as

$$
h=\frac{k \mathrm{Nu}}{L},
$$

where the following Nusselt numbers $\mathrm{Nu}$ were used depending on the section or area of the cabinet under consideration.

For horizontal plate:

Above heated plate:

$$
\begin{aligned}
& \mathrm{Nu}=0.54 \mathrm{Ra}_{L}^{1 / 4} \quad \text { for } 10^{4} \leq \mathrm{Ra}_{L} \leq 10^{9}, \\
& \mathrm{Nu}=0.15 \mathrm{Ra}_{L}^{1 / 3} \quad \text { for } 10^{7} \leq \mathrm{Ra}_{L} \leq 10^{11} .
\end{aligned}
$$

Below heated plate:

$$
\mathrm{Nu}=0.274 \mathrm{Ra}_{L}^{1 / 4} \quad \text { for } 10^{5} \leq \mathrm{Ra}_{L} \leq 10^{10} .
$$

For vertical heated plate:

$$
\begin{array}{r}
\mathrm{Nu}=0.68+\frac{0.67 \mathrm{Ra}_{L}^{1 / 4}}{\left(1+(0.492 / \mathrm{Pr})^{9 / 16}\right)^{4 / 9}} \\
\mathrm{Ra}_{L} \leq 10^{9},
\end{array}
$$

where $\mathrm{Ra}_{L}=\mathrm{Gr} * \operatorname{Pr}$. However, the analysis will not be shown in detail as the values of the heat transfer are more important and are calculated using the above Nusselt numbers. In all cases, the air in the environment is assumed to be still; therefore, the heat transfer coefficients, at the outside of the dryer, are taken as zero. Also, the analysis is based on the assumption that the shutter is fully opened; that is, the crosssectional area is $0.0084 \mathrm{~m}^{2}$.

3.1.1. Collector Analysis. The above properties of air are used for the analysis of the collector.

Heat Absorbed by Radiation in the Collector $Q_{\text {rad,in }}$ :

$$
Q_{\mathrm{rad}, \mathrm{in}}=\alpha A_{c} I
$$

where, $\alpha$ is the absorptivity of the metal; $A_{c}$ is the surface area of the collector exposed to sunshine, and it is equivalent to $0.7 \mathrm{~m}^{2} . I$ is the total incident solar input, and it is expressed as

$$
I=\frac{\text { hourly radiation }}{\text { daily radiation }} \times \text { Solar irradiation, }
$$

where the ratio of the hourly and daily radiation is approximately $0.17(1 / 6)[10]$.

Heat Loss by Convection and Conduction through the Base of the Collector $Q_{\mathrm{cb}, \mathrm{loss}}$ :

$$
Q_{\mathrm{cb}, \mathrm{loss}}=\frac{\Delta T_{\mathrm{cb}}}{\sum R_{\mathrm{cb}}}
$$

where $\Delta T_{\mathrm{cb}}$ is the temperature difference between the collector and the environment. $\sum R_{\mathrm{cb}}=1 / h_{\mathrm{cb}} A_{\mathrm{cb}}+x / k A_{\mathrm{cb}}$ is the thermal resistance offered by the wall and film at the inside of the collector taking the heat transfer coefficient at the outside of the wall as zero (still air). $A_{\mathrm{cb}}$ is the base area of the collector and its value is $0.5 \mathrm{~m}^{2} . h_{\mathrm{cb}}$ is calculated from (2) and (3b).

Useful Heat in the Collector $Q_{u}$ :

$$
Q_{u}=\dot{m} c_{p}\left(T_{c}-T_{a}\right)=Q_{\text {rad,in }}-Q_{\text {cb,loss }} .
$$

Collector Efficiency $\eta_{c}$ :

$$
\eta_{c}=\frac{Q_{u}}{Q_{\text {rad,in }}} \times 100 \% .
$$

3.1.2. Cabinet Analysis. For the analysis of the drying cabinet, the properties of the air are evaluated at the bulk temperature $T=(47.38+41.56) / 2+273^{\circ} \mathrm{C}, \beta=1 / T=3.15 \times 10^{-3} \mathrm{~K}^{-1}$, $\Delta T=47.38{ }^{\circ} \mathrm{C}-41.56{ }^{\circ} \mathrm{C}, \operatorname{Pr}=0.7042, k=0.02756 \mathrm{~W} / \mathrm{m} \cdot{ }^{\circ} \mathrm{C}$, $\rho=1.1147 \mathrm{~kg} / \mathrm{m}^{3}, c_{p}=1.0066 \mathrm{~kJ} / \mathrm{kg} \cdot{ }^{\circ} \mathrm{C}, \mu=1.9261 \times$ $10^{-5} \mathrm{~kg} / \mathrm{m} \cdot \mathrm{s}, \nu=17.463 \times 10^{-6} \mathrm{~m}^{2} / \mathrm{s}$. 
Heat Absorbed by Radiation in the Cabinet $Q_{\mathrm{rad}, \mathrm{in}}$ :

$$
Q_{\mathrm{rad}, \text { in }}=\alpha A_{d} I,
$$

where, $A_{d}=1.5416 \mathrm{~m}^{2}$ is the total area of the cabinet through which radiant heat is absorbed.

Heat Transfer through the Wall of the Collector Case (Greenhouse) into the Cabinet $Q_{\mathrm{gc}, \mathrm{in}}$ :

$$
Q_{\mathrm{gc}, \mathrm{in}}=\frac{\Delta T_{\mathrm{gc}}}{\sum R_{\mathrm{gc}}},
$$

where, $\Delta T_{\mathrm{gc}}=T_{\mathrm{ca}}-T_{d}$ and $\sum R_{\mathrm{gc}}=1 / h_{\mathrm{gc}} A_{\mathrm{gc}}+x / k A_{\mathrm{gc}} \cdot h_{\mathrm{gc}}$ is the heat transfer coefficient at the inside vertical wall of the cabinet and it is calculated using (2) and (3d). $A_{\mathrm{gc}}=0.05 \mathrm{~m}^{2}$ is the area of the portion of the vertical wall separating the cabinet and the collector case.

Heat Radiated to the Environment by Cabinet $Q_{\text {rad,out }}$ :

$$
Q_{\mathrm{rad}, \mathrm{out}}=\varepsilon_{m} \sigma A_{d}\left(T_{d}^{4}-T_{a}^{4}\right),
$$

where, $\varepsilon_{m}$ is the emissivity of the metal, $\sigma=5.669 \times$ $10^{-8} \mathrm{~W} / \mathrm{m}^{2} . K^{4}$ is the Stefan-Boltzmann constant and $A_{d}$ $=1.5416 \mathrm{~m}^{2}$ is the total surface area of the cabinet through which heat is exchanged by radiation with the environment.

Heat Transfer from the Cabinet through the Side Wall $Q_{\mathrm{vc}}$ :

$$
Q_{\mathrm{vc}}=\frac{\Delta T_{d a}}{\sum R_{\mathrm{vc}}},
$$

where $\Delta T_{d a}=T_{d}-T_{a}$ and $\sum R_{\mathrm{vc}}=1 / h_{\mathrm{vc}} A_{\mathrm{vc}}+x / k A_{\mathrm{vc}}$. $A_{\mathrm{vc}}=1.2916 \mathrm{~m}^{2}$ is the area through which heat is transferred by convection and conduction from the side walls of the cabinet to the environment. $h_{\mathrm{vc}}$ is the heat transfer coefficient on the inside of the cabinet around the specified area and it is obtained using (2) and (3d).

Heat Transfer from the Cabinet through the Top Wall $Q_{\mathrm{tc}}$ :

$$
Q_{\mathrm{tc}}=\frac{\Delta T_{d a}}{\sum R_{\mathrm{tc}}}
$$

where, $\Delta T_{d a}=T_{d}-T_{a}$ and $\sum R_{\mathrm{tc}}=1 / h_{\mathrm{tc}} A_{\mathrm{tc}}+x / k A_{\mathrm{tc}} . A_{\mathrm{tc}}=$ $0.25 \mathrm{~m}^{2}$ is the area through which heat is transferred from the lower side of the top of the cabinet to the environment. $h_{\mathrm{tc}}$ is the heat transfer coefficient on the inside of the cabinet around the specified area and is obtained from (2) and (3c).

Heat Transfer from the Cabinet through the Bottom Wall $\mathrm{Q}_{\mathrm{bc}}$ :

$$
\mathrm{Q}_{\mathrm{bc}}=\frac{\Delta T_{d a}}{\sum R_{\mathrm{bc}}}
$$

where $\Delta T_{d a}=T_{d}-T_{a}$ and $\sum R_{\mathrm{bc}}=1 / h_{\mathrm{bc}} A_{\mathrm{bc}}+x / k A_{\mathrm{bc}}$. $A_{\mathrm{bc}}=$ $0.25 \mathrm{~m}^{2}$ is the area through which heat is transferred from the base wall of the cabinet to the environment. $h_{\mathrm{bc}}$ is the heat transfer coefficient at the top surface of the base wall inside

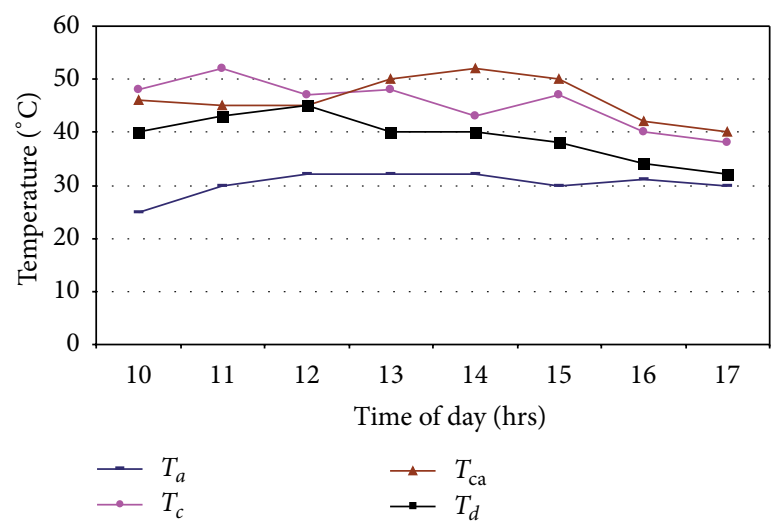

FIGURE 2: Ambient, collector, collector case, and food cabinet temperatures for Day 1.

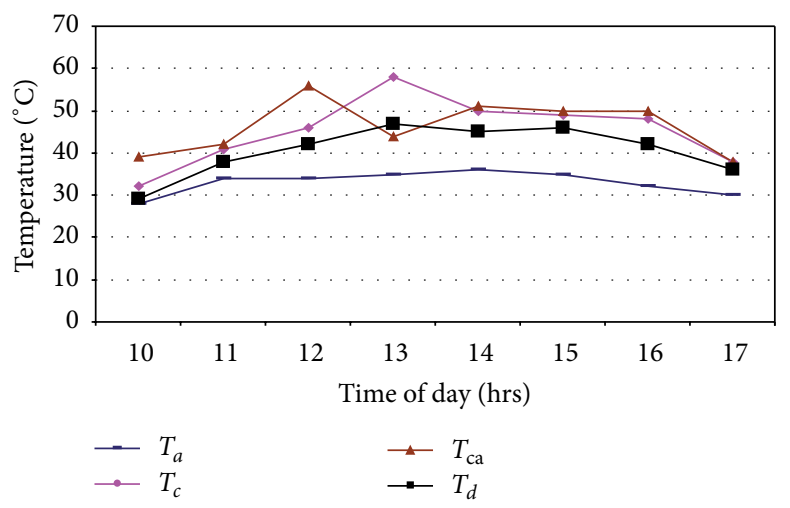

FIGURE 3: Ambient, collector, collector case and food cabinet temperatures for Day 2.

the cabinet around the specified area, and can be evaluated from (2) and (3a).

Total Heat Loss through the Walls of the Cabinet $Q_{\text {loss: }}$ :

$$
Q_{\text {loss }}=Q_{\mathrm{vc}}+Q_{\mathrm{tc}}+Q_{\mathrm{bc}}+Q_{\text {rad,out }} .
$$

Useful Heat in the Cabinet:

$$
Q_{u}=\dot{m} c_{p}\left(T_{c}-T_{d}\right)=Q_{\mathrm{rad}, \text { in }}+Q_{\mathrm{gc}, \text { in }}-Q_{\text {loss }} .
$$

System Efficiency $\eta_{s}$ :

$$
\eta_{s}=\frac{Q_{u}}{Q_{\mathrm{rad}, \text { in }}+Q_{\mathrm{gc}, \text { in }}} \times 100 \% .
$$

\subsection{Drying Analysis}

Percentage Moisture Removed from Product, $\gamma \%$ :

$$
\gamma \%=\frac{\left(m_{w}-m_{d}\right)}{m_{w}} 100 \% \text { wet basis }
$$

where $m_{w}$ and $m_{d}$ are the masses of wet and dried products, respectively. 


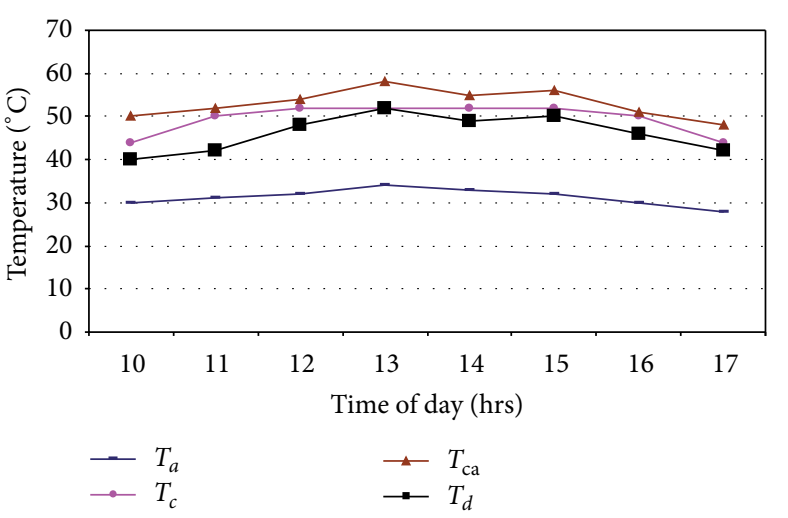

Figure 4: Ambient, collector, collector case, and food cabinet temperatures for Day 3.

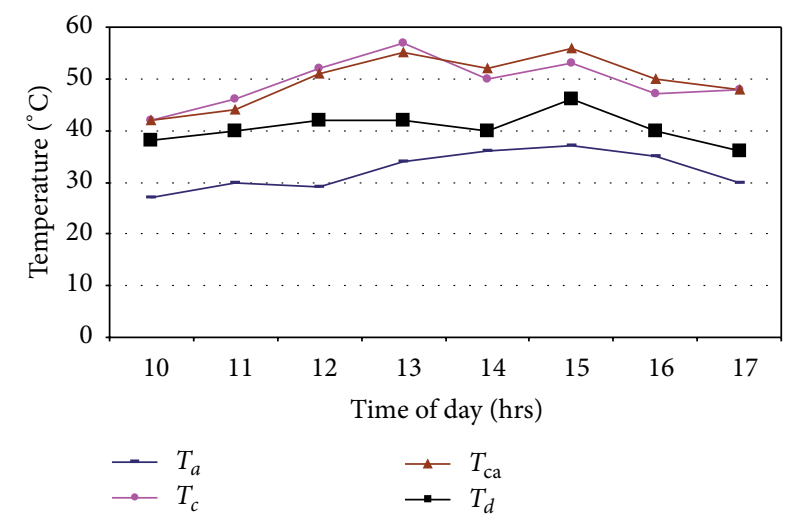

FIgURE 5: Ambient, collector, collector case, and food cabinet temperatures for Day 4.

Final Percentage Moisture Content of Product, $m_{f}$ :

$$
m_{f}=\frac{(100-\gamma)}{100} m_{i},
$$

where $m_{i}$ is the initial mass of the product.

Amount of Moisture Content Removed, $m$ :

$$
m=\frac{m_{w}\left(m_{i}-m_{f}\right)}{100-m_{f}} .
$$

Quantity of Heat Used in Evaporating Moisture, $q_{e}$ :

$$
q_{e}=m h_{\mathrm{fg}}
$$

where $h_{\mathrm{fg}}$ is the latent heat of vaporisation and it is defined by Youcef-Ali et al. [19] as:

$$
h_{\mathrm{fg}}=4.186 \times 10^{3}\left(597-0.56 T_{d}\right) .
$$

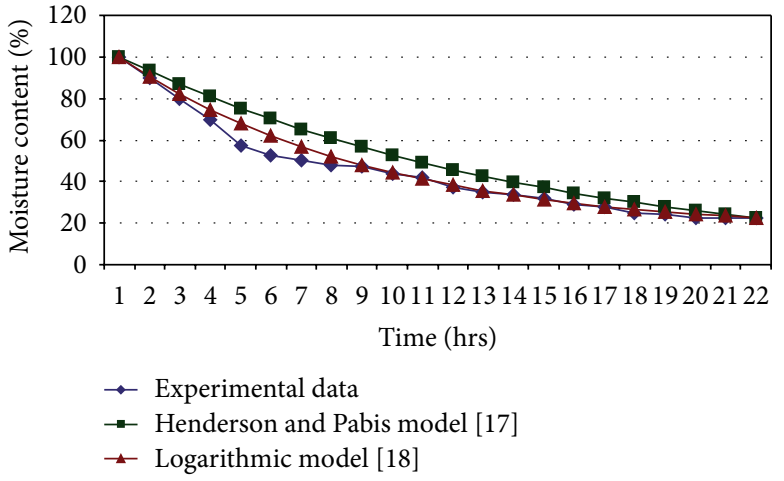

Figure 6: Percentage moisture content removal in the dried plantain fillet compared with two drying models.

Average Drying Rate, $m_{\text {ave }}$ :

$$
m_{\mathrm{ave}}=\frac{m}{t}
$$

where $t$ is daily sunshine hours.

Drying Time, $\delta$ :

$$
\delta=\frac{m h_{\mathrm{fg}}}{3600 I A_{T} t \eta_{c} \eta_{s}} .
$$

\section{Experimental Procedure and Testing}

The assembly was carefully checked to minimise heat loss. It was positioned in such a way that the food cabinet does not cast a shadow on the collector. The plantain fingers were sliced to about $3 \mathrm{~mm}$ thickness and were weighed to determine the initial mass. Four thermometers were placed at strategic locations on the assembly to measure the temperatures of the ambient, collector, collector case, and cabinet. The chimney shutter was adjusted to between $42 \mathrm{~cm}^{2}$ and $84 \mathrm{~cm}^{2}$ space in order to control the mass flow rate, hence, the temperature within the cabinet. The experiment was carried out in October. The first reading was taken at about 10:00 each day, when the sun was just coming up and subsequently on an hourly basis till around 17:00.

\section{Results and Discussion}

The general trend in the profiles of the temperatures obtained shows increases from 10:00 to between 13:00 and 15:00 then decline (Figures 2, 3, 4 and 5). The collector channel and collector case temperatures have higher values than the cabinet and ambient. Though the collector case temperature is always higher, the collector had higher values in Figures 2 and 5 before 14:00. Maximum temperatures of $58^{\circ} \mathrm{C}, 58^{\circ} \mathrm{C}, 52^{\circ} \mathrm{C}$, and $37^{\circ} \mathrm{C}$ were recorded for the collector, collector case, cabinet, and ambient, respectively. Of particular interest is the temperature obtained in the 
TABLE 2: Performance evaluation of the system.

\begin{tabular}{|c|c|c|c|}
\hline$S / N$ & Parameters & Values & Equations used \\
\hline 1 & Heat absorbed by radiation into the collector, $Q_{\text {rad,in }}$ & $132.35 \mathrm{~W}$ & (4) \\
\hline 2 & Total solar input, $I$ & $727.22 \mathrm{~W} / \mathrm{m}^{2}$ & (5) \\
\hline 3 & Heat loss by conduction and convection through the base of the collector, $Q_{c b, l o s s}$ & $70.99 \mathrm{~W}$ & $(6)$ \\
\hline 4 & Useful heat in collector, $Q_{u}$ & $61.36 \mathrm{~W}$ & (7) \\
\hline 5 & Collector efficiency, $\eta_{c}$ & $46.4 \%$ & $(8)$ \\
\hline 6 & Heat absorbed by radiation in cabinet, $Q_{\text {rad,in }}$ & $291.48 \mathrm{~W}$ & (9) \\
\hline 6 & Heat transfer from collector case into cabinet, $Q_{\mathrm{gc}, \text { in }}$ & $0.97 \mathrm{~W}$ & (10) \\
\hline 7 & Heat radiated by cabinet surface, $Q_{\text {rad,out }}$ & $26.64 \mathrm{~W}$ & (11) \\
\hline 8 & Heat transfer from cabinet side wall by cond/conv, $Q_{\mathrm{vc}}$ & $27.94 \mathrm{~W}$ & (12) \\
\hline 9 & Heat transfer from cabinet top wall by cond/conv, $Q_{t c}$ & $2.74 \mathrm{~W}$ & (13) \\
\hline 10 & Heat transfer from cabinet bottom by cond/conv, $Q_{b c}$ & $4.89 \mathrm{~W}$ & (14) \\
\hline 11 & Total heat loss from cabinet, $Q_{\text {loss }}$ & $62.21 \mathrm{~W}$ & (15) \\
\hline 12 & Useful heat in cabinet, $Q_{u}$ & $230.24 \mathrm{~W}$ & (16) \\
\hline 13 & System efficiency, $\eta_{s}$ & $78.73 \%$ & (17) \\
\hline 14 & Percentage moisture removed from product, $\gamma \%$ & $77.5 \%$ & $(18)$ \\
\hline 15 & Final moisture content of product, $m_{f}$ & $15.75 \%$ & $(19)$ \\
\hline 16 & Amount of moisture content removed, $m$ & $1.29 \mathrm{~kg}$ & $(20)$ \\
\hline 17 & Quantity of heat used in evaporation, $q_{e}$ & $3.1 \times 10^{6} \mathrm{MJ}$ & $(21)$ \\
\hline 18 & Average drying rate, $m_{\text {ave }}$ & $0.184 \mathrm{~kg} / \mathrm{hr}$ & $(23)$ \\
\hline 19 & Drying time, $\delta$ & $(0.213 / \text { day })^{-1}$ & $(24)$ \\
\hline
\end{tabular}

TABLE 3: Mathematical models applied to drying curves.

\begin{tabular}{lccc}
\hline$S / N$ & Model name & Model & $k$ \\
\hline 1 & Henderson and Pabis & $X_{m}=100 e^{-k t}$ & 0.071 \\
2 & Logarithmic & $X_{m}=\left(100-m_{f}\right) e^{-k t}+m_{f}$ & 0.1202 \\
\hline
\end{tabular}

cabinet, $52^{\circ} \mathrm{C}$, which is in the range proposed as the optimum temperature for drying fruits and vegetables [20, 21].

From (1) to (24), the results used for the evaluation of the system are presented in Table 2 . The collector efficiency obtained was $46.4 \%$ and system efficiency was $78.73 \%$.

The collector efficiency obtained here is greater than $40 \%$ by Tarigan and Tekasakul [22]. Figure 6 shows the profile of the percentage moisture content. In general, it follows an exponentially decaying pattern before remaining constant at the 20th hour, which indicates about $78 \%$ moisture content removal. This profile pattern is exponentially decaying, and when compared with Henderson and Pabis [17] and Logarithmic models [18] constants, $k$ was obtained as shown in Table 3. It can be seen that the Logarithmic model better predicts the moisture content profile when compared with the Henderson and Pabis model. A critical observation of the experimental data and the models shows some noticeable disparity between the second and ninth hour. A closer look further reveals that the maximum deviation takes place during the fifth and sixth hour. At the beginning of the experiment, it was easier for the produce to lose much of its water content than much later. Moreover, the rate of water moisture loss is proportional to the intensity of the heat energy, hence, the temperature of the cabinet which was always at its peak between thirteen and fifteen hours. Before and after this peak period, the rate of loss was low. It was during this initial period that the model failed to predict the experimental data. The cost of constructing a unit system from locally available materials is tabulated in (Table 4).

\section{Cost Analysis}

The materials were locally available, and the cost for the construction of a unit is tabulated below in the local currency, Naira, and the equivalent in US dollars. The cost per unit is affordable for small and medium manufacturing enterprises (SMMEs) [23].

\section{Conclusion}

The analyses are comprehensive but exclude the structural aspect, mainly because the system is not really a heavyload carrying structure. Assessing the design based on the performance evaluation during the testing, collector and system efficiencies of $46.4 \%$ and $78.73 \%$, percentage moisture removal of $77.5 \%$, final moisture content of plantain chips of $15.75 \%$, and average drying rate of $0.184 \mathrm{~kg} / \mathrm{hr}$ show that the system is both efficient and effective. However, mass production of the system will further reduce the unit cost. To encourage domestic applications in the rural communities, government could subsidise or give a loan with low interest rates. 
TABLE 4: Cost of constructing a unit solar dryer.

\begin{tabular}{lccccc}
\hline Material & Dimension & Quantity & Unit cost, N & Total, N & Total, \$ \\
\hline Mild steel & $0.1 \times 0.2 \mathrm{~m}^{2}$ & 2 & 6,600 & 13,200 & 4,500 \\
Angle iron & $0.2 \mathrm{~m}$ & 3 & 1,500 & 6,000 & 30 \\
Perspex & $0.12 \times 0.24 \mathrm{~m}^{2}$ & $1 / 2$ & 12,000 & 2,000 & 40 \\
Wire gauze & $0.1 \times 0.2 \mathrm{~m}^{2}$ & $1 / 2$ & 4,000 & 1,500 & 1,200 \\
Wood & $0.02 \times 0.1 \mathrm{~m}^{2}$ & 4 & 1,200 & 800 & 8 \\
Sealant & & 1 & 800 & 29,200 & 5.3 \\
Paint & & & & & 2900 \\
\hline Grand total & & & & & 194.6 \\
\hline
\end{tabular}

For exchange rate of 1 US $\$=\mathrm{N} 150.00$.

\section{Nomenclature}

A: $\quad$ Surface area, $\mathrm{m}^{2}$

$c_{p}$ : Specific heat at constant pressure, $\mathrm{kJ} / \mathrm{kg} \cdot{ }^{\circ} \mathrm{C}$

$g$ : Acceleration due to gravity, $\mathrm{m} / \mathrm{s}^{2}$

Gr: Grashof number

$h$ : Heat transfer coefficient, $\mathrm{W} / \mathrm{m}^{2} \cdot{ }^{\circ} \mathrm{C}$

$h_{\mathrm{fg}}$ : Latent heat of vaporisation, $\mathrm{MJ} / \mathrm{kg}$

I: $\quad$ Solar insolation of collector, $\mathrm{W} / \mathrm{m}^{2}$

$k$ : $\quad$ Thermal conductivity, $\mathrm{W} / \mathrm{m} \cdot{ }^{\circ} \mathrm{C}$

L: $\quad$ Length, $\mathrm{m}$

$\dot{m}$ : Mass flow rate, $\mathrm{kg} / \mathrm{s}$

$m$ : Mass, $\mathrm{kg}$

Nu: Nusselt number

Pr: Prandtl number

$q_{e}:$ Heat of vapourisation, MJ

Q: Heat transfer rate, $\mathrm{W}$

$\mathrm{Ra}_{L}:$ Rayleigh number

$x$ : Thickness of metal sheet, $\mathrm{m}$

$X_{m}$ : Percentage moisture content at any time $t, \%$

$t$ : Sunshine hours (Time), hrs

T: $\quad$ Temperature, ${ }^{\circ} \mathrm{C}$

$\Delta T$ : Temperature difference, ${ }^{\circ} \mathrm{C}$

$\Sigma R$ : Total thermal resistance, ${ }^{\circ} \mathrm{C} / \mathrm{W}$.

\section{Greek Letters}

$v$ : Kinematic viscosity, $\mathrm{m}^{2} \mathrm{~s}$

$\mu$ : Dynamic viscosity, $\mathrm{kg} / \mathrm{m} \cdot \mathrm{s}$

$\beta$ : Coefficient of thermal expansion $\mathrm{K}^{-1}$

$\delta$ : Drying time, days.

$\tau$ : Transmittance

$\rho$ : Density, $\mathrm{kg} / \mathrm{m}^{3}$

$\alpha$ : Absorptivity

$\varepsilon$ : Emissivity

$\sigma$ : Stefan-Boltzmann constant, $\mathrm{W} / \mathrm{m}^{2} \mathrm{~K}^{4}$

$\eta$ : Efficiency, \%

$\gamma$ : Moisture removal, $\%$

\section{Subscript}

a: Ambient

ave: Average

$\begin{array}{ll}\text { bc: } & \text { Base of cabinet } \\ c: & \text { Collector } \\ \text { ca: } & \text { Collector case } \\ d: & \text { Drying cabinet, dried product } \\ d a: & \text { Drying cabinet to environment } \\ f: & \text { Final } \\ \text { gc: } & \text { Collector case (greenhouse) to cabinet } \\ i: & \text { Inlet, initial } \\ m: & \text { Metal } \\ \text { loss: } & \text { Heat loss to the environment } \\ \text { rad out: } & \text { Radiation outward } \\ \text { rad in: } & \text { Radiation into } \\ \text { tc: } & \text { Top of cabinet } \\ T: & \text { Total } \\ u: & \text { Useful } \\ v c: & \text { Vertical sides of cabinet } \\ w: & \text { Wet product. }\end{array}$

\section{References}

[1] B. K. Bala, M. A. Ashraf, M. A. Uddin, and S. Janjai, "Experimental and neural network prediction of the performance of a solar tunnel drier for drying jackfruit bulbs and leather," Journal of Food Process Engineering, vol. 28, no. 6, pp. 552-566, 2005.

[2] V. K. Sharma, A. Colangelo, and G. Spagna, "Experimental investigation of different solar dryers suitable for fruit and vegetable drying," Renewable Energy, vol. 6, no. 4, pp. 413-424, 1995.

[3] S. Janjai, N. Srisittipokakun, and B. K. Bala, "Experimental and modelling performances of a roof-integrated solar drying system for drying herbs and spices," Energy, vol. 33, no. 1, pp. 91-103, 2008

[4] A. O. Adelaja and S. J. Ojolo, "Design, analysis and experimental evaluation of photovoltaic forced convection solar dryer for the tropics," International Journal of Engineering Research in Africa, vol. 3, pp. 49-61, 2010.

[5] M. M. I. Choudhury, B. K. Bala, and M. A. Hague, "Energy and exergy analysis of the solar drying of jackfruit leather," Biosystems Engineering, vol. 110, pp. 222-229, 2011.

[6] A. O. Adelaja, B. Y. Ogunmola, and P. O. Akolade, "Development of a photovoltaic powered forced convection solar dryer," Advanced Materials Research, vol. 62-64, pp. 543-548, 2009.

[7] A. O. Adelaja, O. S. Asemota, and I. K. Oshiafi, "Experimental determination of the moisture content pattern in yam during drying," Journal of Applied Science Research, vol. 6, no. 8, pp. 1171-1181, 2010. 
[8] I. N. Simate, "Optimization of mixed-mode and indirect-mode natural convection solar dryers," Renewable Energy, vol. 28, no. 3, pp. 435-453, 2003.

[9] B. O. Bolaji and A. P. Olalusi, "Performance evaluation of a mixed-mode solar dryer," AU Journal of Technology, vol. 11, no. 4, pp. 225-231, 2008.

[10] R. O. Fagbenle, "Optimum collector tilt angles and average annual global radiation for Nigerian locations," Nigerian Journal of Renewable Energy, vol. 2, pp. 9-17, 1991.

[11] R. L. Fagbenle, "A comparative study of some simple models for global solar irradiation in Ibadan, Nigeria," International Journal of Energy Research, vol. 16, no. 7, pp. 583-595, 1992.

[12] R. S. Khurmi and J. K. Gupta, A Textbook of Machine Design (S. I. Units), Manufacturing Consideration in Machine Design and Simple Stresses in Machine Parts, 1979.

[13] W. H. McAdams, Heat Transmission, McGraw-Hill, New York, NY, USA, 3rd edition, 1954.

[14] F. B. Mukhtar, "Effect of storage temperatures on post harvest deterioration of banana and plantain (Musa spp.)," International Journal of Pure and Applied Sciences, vol. 3, no. 2, pp. 28-38, 2009.

[15] J. P. Holman, Heat Transfer, Tata McGraw-Hill, 9th edition, 2002.

[16] J. A. Duffie and W. A. Beckman, Solar Engineering of Thermal Processes, John Wiley and Sons, 2nd edition, 1980.

[17] A. Yagcioglu, A. Degirmencioglu, and F. Cagatay, "Drying characteristics of lauel leaves under different conditions," in Proceedings of the 7th International Congress on Agricultural Mechanization and Energy (ICAME '99), pp. 565-569, Faculty of Agriculture, Adana, Turkey, 1999.

[18] O. Yaldiz, C. Ertekin, and H. I. Uzun, "Mathematical modeling of thin layer solar drying of sultana grapes," Energy, vol. 26, no. 5, pp. 457-465, 2001.

[19] S. Youcef-Ali, H. Messaoudi, J. Y. Desmons, A. Abene, and M. Le Ray, "Determinationof the average coefficient of internalmoisture transfer during the drying of a thin bed of potato slices," Journal of Food Engineering, vol. 48, no. 2, pp. 95-101, 2001.

[20] A. Henneman, Drying Vegetable adapted from 'So Easy to Preserve' Cooperative Extension", The University of Georgia, 1993, and Michigan Cooperative Extension Food Preservation Handbook, 1994.

[21] J. Mumba, "Development of a photovoltaic powered forced circulation grain dryer for use in the tropics," Renewable Energy, vol. 6, no. 7, pp. 855-862, 1995.

[22] E. Tarigan and P. Tekasakul, "A mixed-mode natural convection solar dryer with biomass burner and heat storage back-up heater," in Proceedings of the Australia and New Zealand Solar Energy Society Annual Conference, pp. 1-9, 2005.

[23] F. O. Okafor, "Micro-credit: an instrument for economic growth and balance development," Journal of the Management Sciences, vol. 3, no. 2, pp. 24-39, 2000. 


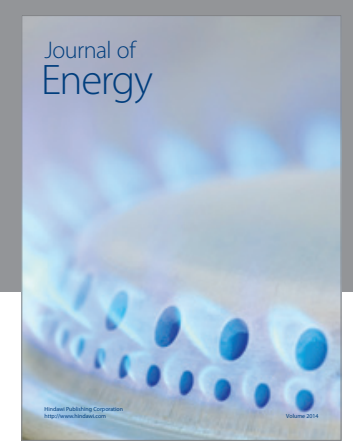

Journal of

Industrial Engineering
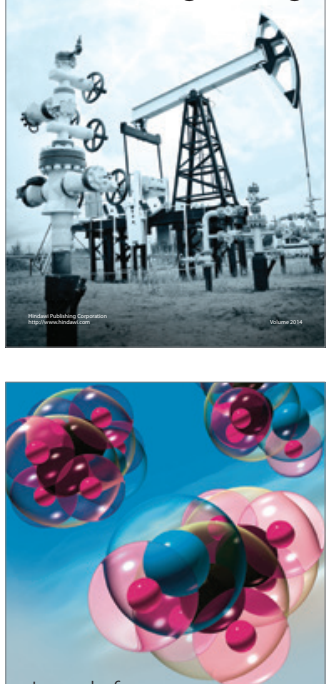

Fuels
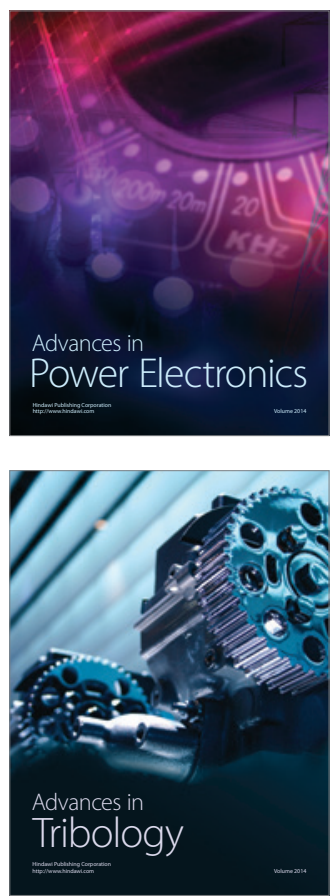

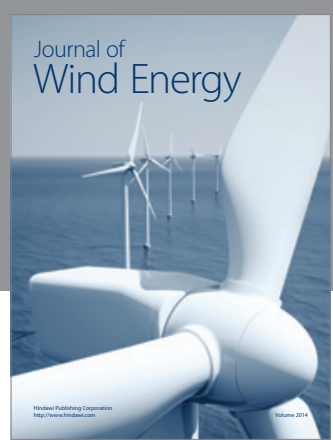

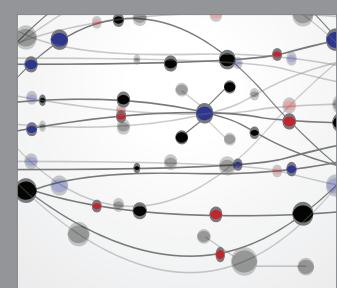

The Scientific World Journal

Submit your manuscripts at http://www.hindawi.com

Journal of

Structures
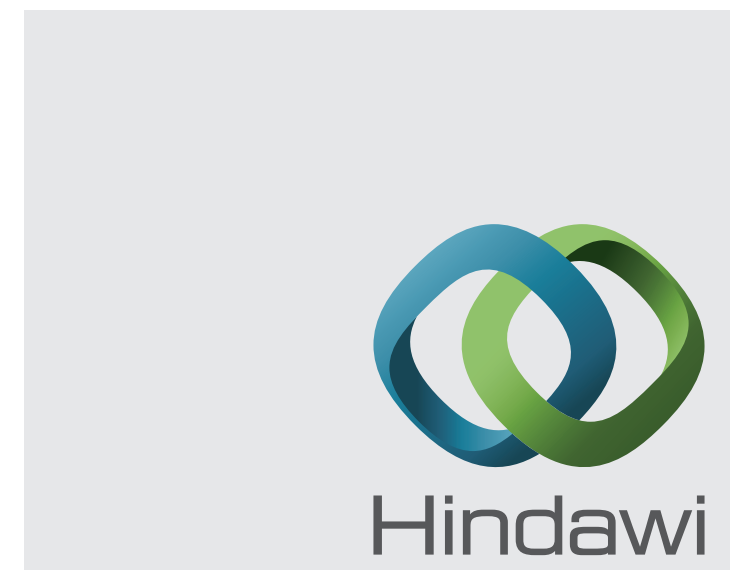

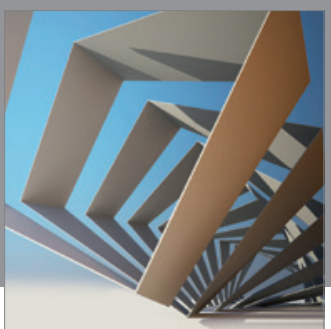

Rotating

Machinery
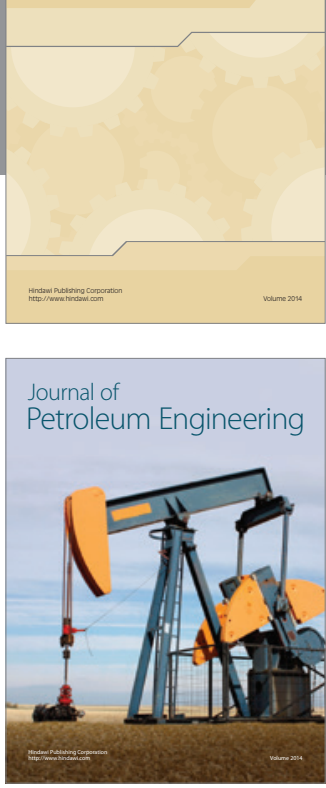

Journal of

Solar Energy
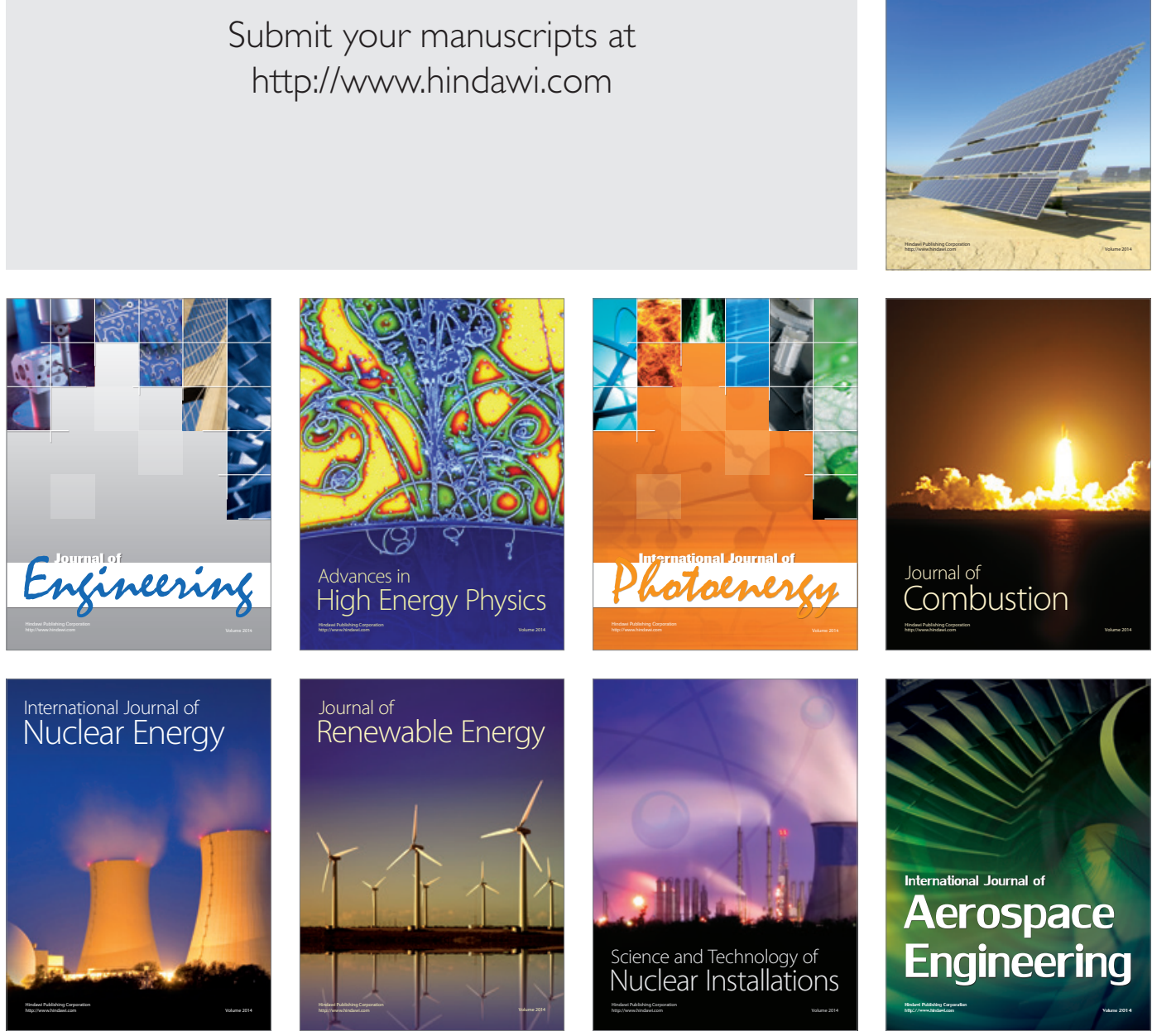